\title{
Particulate manganese, iron and aluminum in coastal water, Funka Bay, Japan
}

\author{
Shizuo Tsunogai and Mitsuo Uematsu \\ Department of Chemistry, Faculty of Fisheries, \\ Hokkaido University, Hakodate 041, Japan
}

(Received June 13, 1977; accepted in revised form September 22, 1977)

\begin{abstract}
Seawater samples collected in a coastal area in Funka Bay, Hokkaido, were analyzed for manganese, iron and aluminum in particulate form and for the total concentrations of manganese and iron. A marked contrast was found in the seasonal variations of their distribution with high concentrations of particulate aluminum in winter and total manganese in summer. The causes of the seasonal variations are the dissolution of manganese from the sea floor and the influx of terrigenous material probably transported by the winter monsoon, although resuspension of particles from the bottom and in situ biological decomposition contribute somewhat to the variations in the lower layers of the bay water. When the particulate matter becomes incorporated into the bottom sediments, the proportions of metals lost from the particles are calculated to be more than $76 \%$ for manganese and $57 \%$ for iron. The rates of resupply to the coastal water estimated from the particulate flux are calculated to be 0.5 and $10 \mathrm{~g} / \mathrm{m}^{2} / \mathrm{yr}$ for manganese and iron, respectively.
\end{abstract}

\section{INTRODUCTION}

Neither iron nor manganese has a stable ionic species when dissolved in oxygenated seawater, and the thermodynamically stable states of those elements are the solid phases of ferric oxide and manganese (IV) oxide, respectively (SILlÉN, 1961; KRAUSKOPF, 1957; KESTER, 1972). The particulate fraction, which is collected on filter paper of about $0.5 \mu \mathrm{m}$ pore size, however, is only about $10 \%$ of the concentration for both elements in the open sea water (SPENCER et al., 1970; BETZER and PILSON, 1970; Brewer et al., 1976). This fact is considered by some authors (e.g. PRICE and CAL VERT, 1973) to indicate that organic matter may form rather stable complexes with these insoluble metals in seawater. There is, however, no definite evidence that the majority of the iron or manganese in seawater exists as organocomplex, although there is strong evidence for the presence of organically-bound copper in seawater (e.g. Williams, 1969; SPENCER and S ACHS, 1970).

TsunOGaI et al. (1974) stated that these insoluble metals do not form a true solution in seawater and that their transport from surface water to deep water in the pelagic ocean should be realized by organic or biogenic substances whether or not these metals are chemically associated with organic matter. On this basis, the behavior of the insoluble metals is expected to be similar to each other in seawater. The oceanic residence time which is one measure of reactivity of elements in sea water, however, does show a large difference between manganese (of the order of $10^{3}$ years) and iron $(100-200$ years) in the ocean (GolDBERG and A RRHENIUS, 1958; GolDBERG et al., 1971). Although overestimate of the concentration of manganese in seawater is a cause of the longer residence time of manganese (BREWER, 1975), we have set forth a working hypothesis for the cause of difference in the residence time, namely mechanisms governing the seawater composition. The hypothesis explains the existence of fractionation processes during early diagenesis in pelagic sediments and of processes modifying the composition of these insoluble metals during the active biological productivity and the rapid particulate removal in coastal sea. We (TsuNOGAI and KUSAKABE, 1977) have found evidence of the migration of manganese in pelagic sediments where the conditions of the environment are reducing for manganese but not reducing for iron. Here we try to demonstrate the latter part of the above hypothesis, comparing the chemical composition of coastal sediments 
with that of suspended matter which can be assumed in a first approximation to be the source material of the bottom sediments. The redox potential of coastal sediments is usually so low that ferric compounds may also be reduced to more soluble ferrous compounds. Aluminum is therefore selected as a constant reference standard during the decomposition of organic matter or the early diagenesis of anaerobic bottom sediments.

\section{Sampling and Analytical Methods}

Sampling site and method Observations were carried out at station 1 in Funka Bay, Hokkaido (Fig. 1). The bay was chosen for study because the hydrography of the bay has been relatively well studied (OHTANI and AKIBA, 1970) and a semi-closed model can be applied to the bay. The cold water, the Oyashio, flows into the bay in spring and remains during summer. The Tsugaru warm current, a branch of Kuroshio, begins to mix with the summer water of the bay from late summer to autumn. This mixed water stays until spring. There are no large rivers around the bay and pollution or artificial eutrophication is not yet observed. The lowest concentration of dissolved oxygen found is $1.6 \mathrm{ml} / 1$ in the bottom water in late summer. The bottom is flat and the maximum depth is about $100 \mathrm{~m}$.

The sampling was performed every one or two months from June 1975 to February 1976 on board the R/V Ushio Maru (98 gross tons) of Hokkaido University at station 1 (depth, $92 \mathrm{~m}$ ) and sometimes at station 2 (depth, 102m)

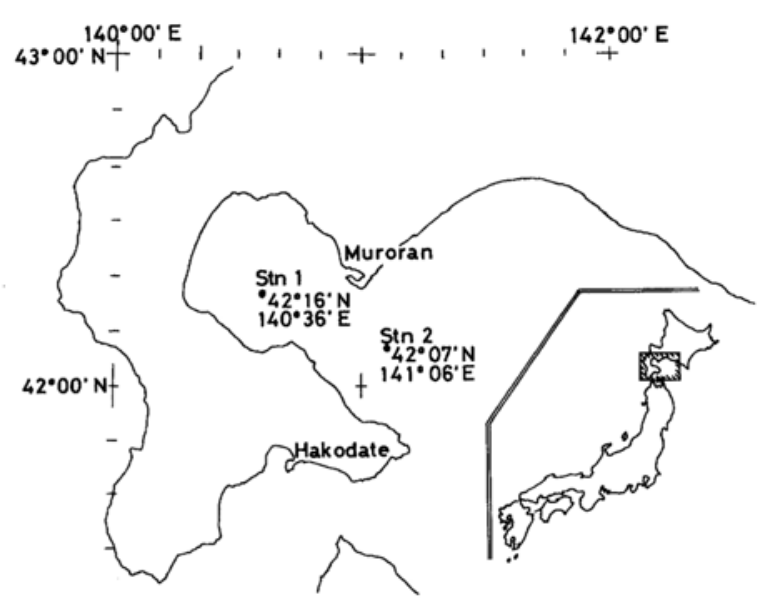

Fig. 1. Sampling sites in Funka Bay. outside the bay (Fig. 1). The seawater samples were coilected with $5 l$ Niskin type samplers made of polyvinyl chloride set at depths every approximately $10 \mathrm{~m}$ from the surface.

Treatment and chemical analysis of samples The procedure is schematically shown in Fig. 2. Within half a day after sampling an aliquot of the sample water was filtered through the membrane filter (Millipore HA type, $0.45 \mu \mathrm{m}$ pore size). The residue on the filter was washed with ammonium carbonate solution to remove sea salts from the particulate matter. The filter was dried in a vacuum drying oven to evaporate the ammonium carbonate. The dry weight of total suspended matter (TSM) was determined from the difference in dry weights of the membrane filter before and after filtration. The concentrations of particulate manganese, iron and aluminum were determined by a flameless atomic absorption method after digesting the filter. The sensitivities were $0.002,0.009$ and $0.007 \mu \mathrm{g}$ for manganese, iron and aluminum, respectively. The overall analytical error was $8 \%$ for manganese, $6 \%$ for iron and $8 \%$ for aluminum at the usually observed concentration levels.

The analytical methods for the total concentrations of manganese and iron are based on those of STRICKLAND and PARSONS (1968) and LEWIN and CHEN (1973), respectively, although the pre-treatment methods were improved as follows. Aliquots of the samples were evaporated almost to dryness and digested with the acid mixtures described in Fig. 2. We found no appreciable amounts of metals adsorbed on the wall of bottles during storage but ignored large particles which settled down from the sample water before making the aliquot. The analytical error in the determination of total concentration was $7 \%$ at the concentration level of $1 \mu \mathrm{g} / 1$ for manganese and $10 \%$

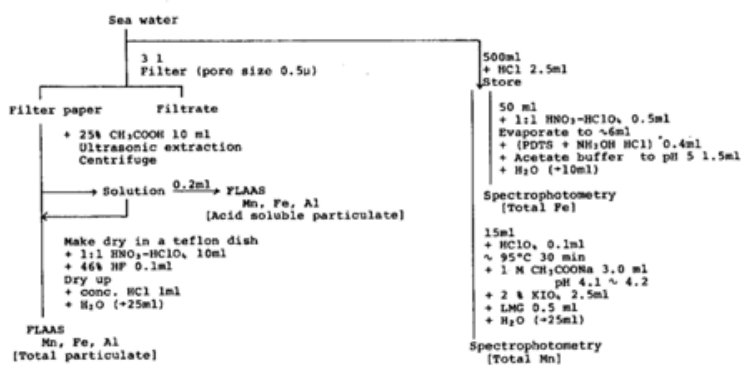

Fig. 2. Analytical procedure. 
at the $10 \mu \mathrm{g} / 1$ level for iron.

\section{Results AND Discussion}

Seasonal and vertical variations of particulate manganese, iron and aluminum The vertical profiles of particulate manganese, iron and aluminum at station 1 on 18 August, 1975 are compared with those on 6 February, 1976 (Figs. 3 and 4). A marked difference is found between the two seasons, namely much higher concentration of aluminum in winter $(19.3 \mu \mathrm{g} / 1$ on an average) than in summer $(2.1 \mu \mathrm{g} / \mathrm{l})$, whereas the concentration of particulate manganese in winter $(0.67 \mu \mathrm{g} / \mathrm{l})$ is smaller than that in summer $(0.90 \mu \mathrm{g} / \mathrm{l})$. This tendency is clearly shown in Table 1 where the observed results are summarized separately for the upper $(0-$ $50 \mathrm{~m})$ and lower $(50-92 \mathrm{~m})$ water layers.

The total dry weight of suspended matter (TSM) is usually higher in the lower layer than in the upper layer. This trend is the same as those for the concentrations of particulate manganese, iron and aluminum and even for

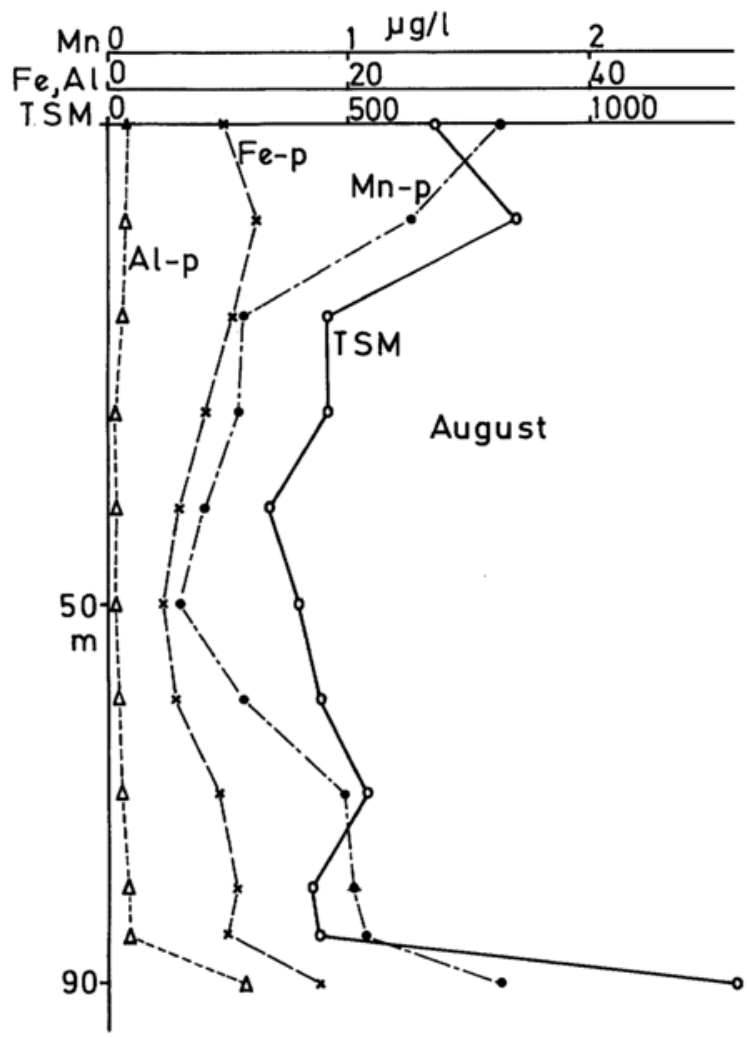

Fig. 3. Vertical profiles of particulate manganese, iron and aluminum for samples collected on 18 August 1975 at station 1. the iron and aluminum contents of the particulate matter, namely the ratios of Fe-p/TSM and Al-p/TSM. This may be due to the resuspension from bottom sediments and/or the slowdown of settling velocity of particles, the organic fraction of which is gradually decomposing.

The concentration of total iron was, sometimes surprisingly lower than that of particulate iron especially in winter when the concentration was high even when analytical error was taken into account. This difference seems to be caused by the large particles of terrigenous alumino-silicate in the coastal seawater, which settled down during storage from the seawater samples before the determination of total element concentrations. It is desirable to determine the concentrations of metals in the filtrate although care must be taken to avoid contamination during the filtration treatment. Our preliminary results showed that the concentration of iron in the filtrate was $3.0 \pm 1.6 \mu \mathrm{g} / 1$ for samples collected in August or $4.4 \pm 1.5 \mu \mathrm{g} / 1$ in February. It is therefore interesting to note

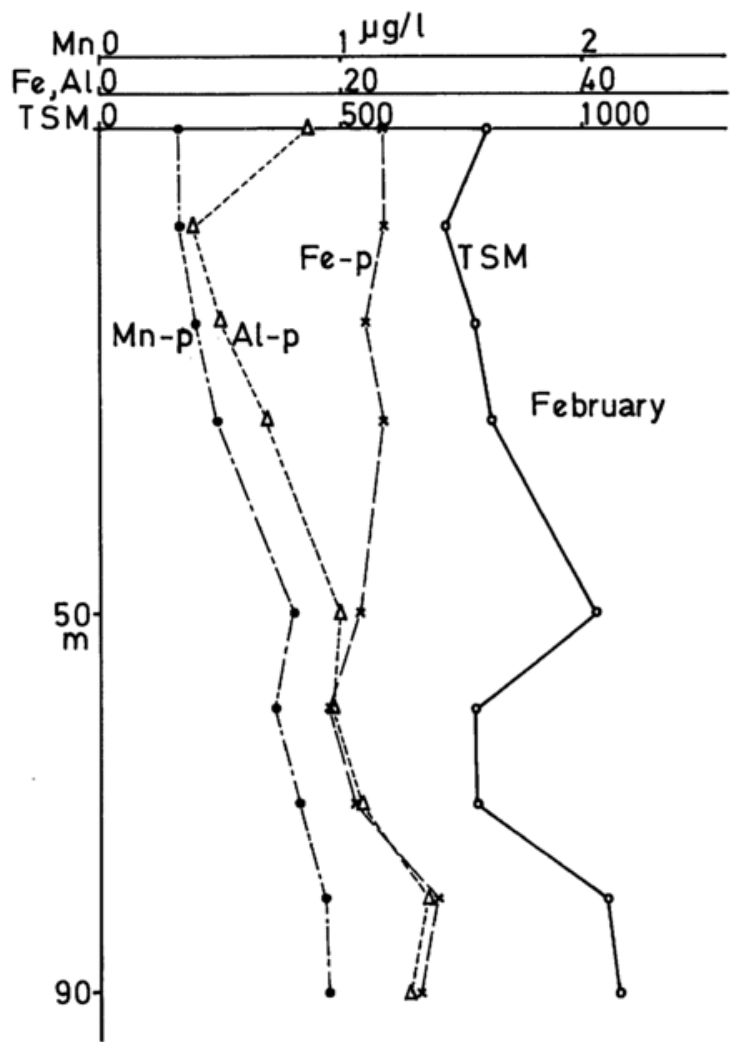

Fig. 4. Vertical profiles of particulate manganese, iron and aluminum for samples collected on 6 February 1976 at station 1. 
Table 1. Concentrations of manganese, iron and aluminum in seawater, sediment and plankton at Station 1 in Funka Bay. The suffixes $t$ and pindicate total and particulate form concentrations, respectively.

\begin{tabular}{|c|c|c|c|c|c|c|c|c|c|}
\hline & $\begin{array}{c}\text { TSM } \\
\mu \mathrm{g} / 1\end{array}$ & $\begin{array}{r}\text { Mn-t } \\
\mu \mathrm{g} / 1\end{array}$ & $\begin{array}{c}\text { Mn-p } \\
\mu \mathrm{g} / 1\end{array}$ & $\begin{array}{c}\frac{\text { Mn-p }}{\text { TSM }} \\
\%\end{array}$ & $\begin{array}{l}\mathrm{Fe}-\mathrm{t} \\
\mu \mathrm{g} / 1\end{array}$ & $\begin{array}{l}\text { Fe-p } \\
\mu \mathrm{g} / 1\end{array}$ & $\begin{array}{c}\text { Fe-p } \\
\text { TSM } \\
\%\end{array}$ & $\begin{array}{l}\text { Al-p } \\
\mu \mathrm{g} / 1\end{array}$ & $\begin{array}{c}\text { Al-p } \\
\text { TSM } \\
\%\end{array}$ \\
\hline Upper layer & \multicolumn{2}{|c|}{$(0-50 m)$} & & & & & & & \\
\hline 10 June & 641 & 2.86 & 0.92 & 0.14 & 8.3 & 7.5 & 1.2 & 1.17 & 0.18 \\
\hline 10 July & 451 & 1.41 & 0.54 & 0.12 & 4.1 & 3.5 & 0.78 & 0.48 & 0.11 \\
\hline 28 Aug. & 527 & 1.91 & 0.78 & 0.15 & 6.8 & 8.4 & 1.6 & 0.99 & 0.19 \\
\hline 29 Sept. & 632 & 1.10 & 0.20 & 0.032 & 7.0 & 11.2 & 1.8 & 1.37 & 0.22 \\
\hline 29 Oct. & 676 & 0.62 & 0.33 & 0.049 & 7.5 & 9.5 & 1.4 & 1.65 & 0.24 \\
\hline 11 Dec. & 682 & 0.84 & 0.32 & 0.047 & 11.8 & 14.9 & 2.2 & 10.3 & 1.5 \\
\hline 6 Feb. & 827 & 0.73 & 0.47 & 0.057 & 18.1 & 22.8 & 2.8 & 13.9 & 1.7 \\
\hline \multicolumn{10}{|l|}{ cf. Stn. 2} \\
\hline 1 Oct. & 546 & 0.48 & 0.24 & 0.044 & 6.8 & 6.6 & 1.2 & 1.34 & 0.25 \\
\hline Lower layer & \multicolumn{2}{|c|}{$(50-92 m)$} & & & & & & & \\
\hline 10 June & 390 & 2.39 & 1.03 & 0.26 & 10.3 & 9.4 & 2.4 & 2.16 & 0.55 \\
\hline 10 July & 710 & 4.77 & 4.32 & 0.61 & 12.0 & 7.9 & 1.1 & 11.2 & 1.6 \\
\hline 28 Aug. & 625 & 2.19 & 1.05 & 0.17 & 8.1 & 10.6 & 1.7 & 3.45 & 0.55 \\
\hline 29 Sept. & 814 & 3.59 & 1.12 & 0.14 & 14.5 & 14.6 & 1.8 & 4.22 & 0.52 \\
\hline 29 Oct. & 884 & 0.78 & 0.62 & 0.070 & 9.8 & 10.4 & 1.2 & 4.16 & 0.47 \\
\hline 11 Dec. & 726 & 0.84 & 0.31 & 0.043 & 20.8 & 18.4 & 2.5 & 19.1 & 2.6 \\
\hline 6 Feb. & 922 & 0.96 & 0.86 & 0.093 & 17.2 & 23.7 & 2.6 & 23.5 & 2.5 \\
\hline \multicolumn{10}{|l|}{ cf. Stn. 2} \\
\hline 1 Oct. & 713 & 1.24 & 0.33 & 0.046 & 27.1 & 16.0 & 2.2 & 11.9 & 1.7 \\
\hline \multicolumn{3}{|c|}{ Sediments, surface } & & 0.039 & & & 2.8 & & 5.4 \\
\hline \multicolumn{9}{|l|}{ Plankton } & 0.36 \\
\hline
\end{tabular}

that the coastal water contains rather small amounts of iron in dissolved and micro colloidal forms (cf. $5.0 \mu \mathrm{g} \mathrm{Fe} / 1$ in the filtrate of the North Pacific water, SPENCER et al., 1970).

Manganese and aluminum in the upper water layer show a remarkable seasonal variations (Table 1). As will be discussed later, the dissolution and release of manganese from bottom sediments increase the concentration of manganese in the stagnant summer water. In late September when the upper water was displaced by the warm open sea water, the concentration of particulate manganese decreases considerably, since the manganese concentration in the pelagic water is one or two orders of magnitude smaller than that in the bay. The total concentration of manganese even in the lower layer in late October decreased to about a half of the value in September. Conversely, the concentration of aluminum together with that of particulate iron abruptly increased in December. Although the present data can not completely exclude the possibility of turbulent transfer of settling particles from the nearly $100 \mathrm{~m}$ deep bottom to the surface at a rate of more than $1 \mathrm{~m} /$ day in winter, we attribute this high alumino-silicate content of the surface water to continental dust transported by the active winter-monsoon (Tsunogai and Shinagawa, 1977). The rate of erosion of the land surface covered by snow in winter is, of course, smaller than that in summer.

The ratios of $\mathrm{Mn} / \mathrm{Al}$ and $\mathrm{Fe} / \mathrm{Al}$ (Table 2) also support the above conclusions that there is a large source of manganese and iron in summer and that suspended particles are diluted by terrigenous material in winter.

Loss of manganese from the suspended matter to seawater The relation between aluminum

Table 2. Ratios of Mn/Al and Fe/Al for suspended matter, plankton and sediments collected at Station 1.

\begin{tabular}{rll}
\hline \hline & $\mathrm{Mn} / \mathrm{Al}$ & $\mathrm{Fe} / \mathrm{Al}$ \\
\hline Suspended matter & & \\
28 Aug. $\begin{array}{l}\text { upper layer } \\
\text { lower layer }\end{array}$ & 0.79 & 8.5 \\
& 0.30 & 3.1 \\
6 Feb. $\quad \begin{array}{l}\text { upper layer } \\
\text { lower layer }\end{array}$ & 0.032 & 1.66 \\
Plankton & 0.037 & 1.01 \\
$\quad$ 28 Aug. & 0.033 & 1.81 \\
$\begin{array}{l}\text { Sediments } \\
\text { cf. Crust }\end{array}$ & 0.0072 & 0.52 \\
(TAYLOR, 1964) & 0.0012 & 0.68 \\
\hline
\end{tabular}


and total suspended matter (TSM) at station 1 is plotted in Fig. 5. The solid line in the figure shows the concentration of aluminum in the surface sediments of the same station (Table 1) and the dotted lines are the regression lines calculated separately from the observed values in summer and winter. These observed points in Fig. 5 are far to the right from the sediment line. In winter the gradient of the regression line is slightly lower than that of sediment line but an extremely gentle slope is observed in summer as summarized in Table 3 . The segments of the two season's regression lines on the TSM axis in Fig. 5, namely the amount of TSM for nought concentration of aluminum, coincide fairly well at about $400 \mu \mathrm{g} / \mathrm{l}$. These

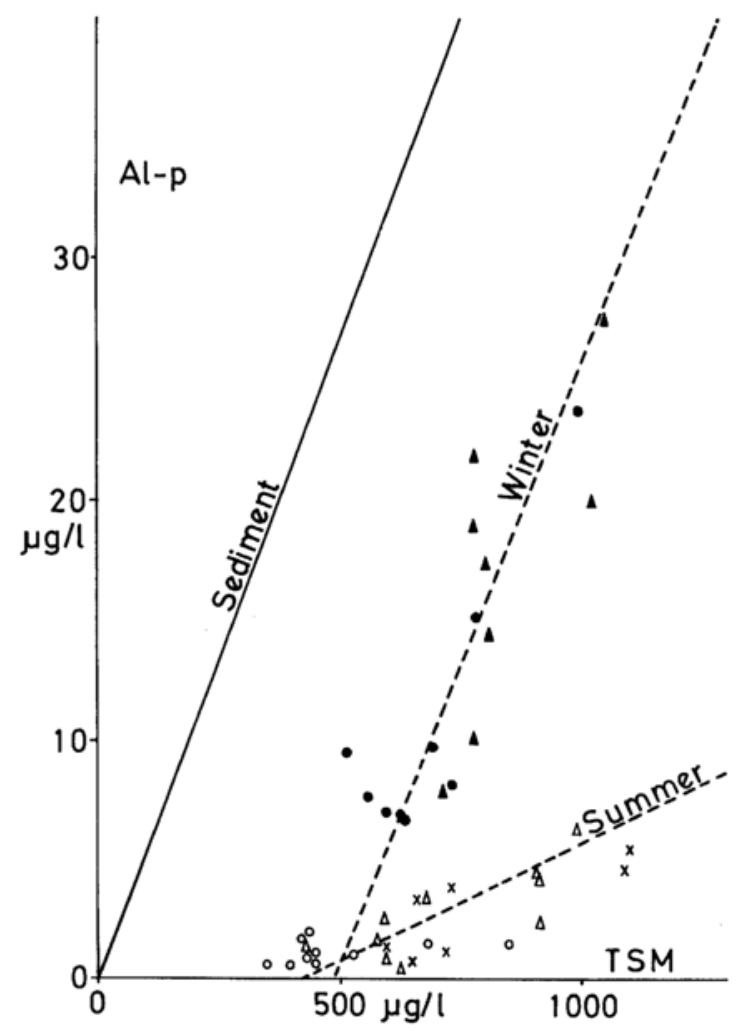

Fig. 5. Relation between particulate aluminum and total suspended matter (TSM) for samples collected on 18 August (O), 29 September ( $\triangle$ ), 29 October (X), 11 December ( $\bullet$ ) and 6 February (४) at station 1. A regression line denoted as summer is calculated from samples obtained in August and September and that denoted as winter is from samples obtained in December and February. A solid line shows the concentration in sediments.
Table 3. Gradients and segments of the regression lines of the metals in particulate form against TSM for samples excluding the deepest samples collected in summer (28 August and 29 September) and in winter (11 December and 6 February).

\begin{tabular}{lcccc}
\hline \hline & \multicolumn{2}{c}{ Summer } & \multicolumn{2}{c}{ Winter } \\
\cline { 2 - 5 } & $\begin{array}{c}\text { Gradient } \\
(\mathrm{M} / \mathrm{TSM}) \times 10^{2}\end{array}$ & $\begin{array}{c}\text { Segment* } \\
\mu \mathrm{g} / \mathrm{l}\end{array}$ & $\begin{array}{c}\text { Gradient } \\
(\mathrm{M} / \mathrm{TSM}) \times 10^{2}\end{array}$ & $\begin{array}{c}\text { Segment* } \\
\mu \mathrm{g} / 1\end{array}$ \\
\hline $\mathrm{Al}$ & 1.0 & 420 & 5.1 & 490 \\
$\mathrm{Fe}$ & 2.9 & 240 & 5.9 & 450 \\
$\mathrm{Mn}$ & 0.50 & 460 & 0.20 & 530 \\
\hline
\end{tabular}

* On the TSM axis in Figs. 5-7, which indicate the concentration of TSM at nought concentration level of each metal.

facts suggest that the particulate material can be divided into two fractions. One is the fraction which contains negligible amounts of aluminum. This fraction probably consists of biogenic material or material which can be easily decomposed or altered to soluble material. We designate this as "soluble fraction". The other fraction is the "insoluble fraction" which contains nearly the same amount of aluminum as that in the sediments, $5.4 \%$. The soluble fraction largely contributes to the increase of TSM in summer and amounts to at least $400 \mu \mathrm{g} / 1$ in all seasons. The increase of TSM in winter is chiefly due to the addition of the insoluble fraction. This suggestion does not contradict other observations in the bay such as the active primary production in summer (M AITA and YANADA, 1977) and the seasonal and vertical changes of the inorganic fraction of particulate matter (Tsunogai and Arita, 1975).

The relation between iron and TSM is shown in Fig. 6. The plotted data are distributed near the sediment line and the regression line of iron observed in winter and especially that in summer are steeper than those of aluminum as normalized to the sediment line. By combining this result with the discussion for aluminum, it is considered that the soluble fraction contains a part of iron in the particulate matter.

The calculated slopes for manganese (Fig. 7) are the steepest. This implies that the particulate matter is extremely enriched in manganese and loses most of its manganese before it settles on and forms bottom sediments. This loss of manganese from particulate matter is discussed more quantitatively as follows.

We assume that the settling particulate matter changes its chemical composition to that 


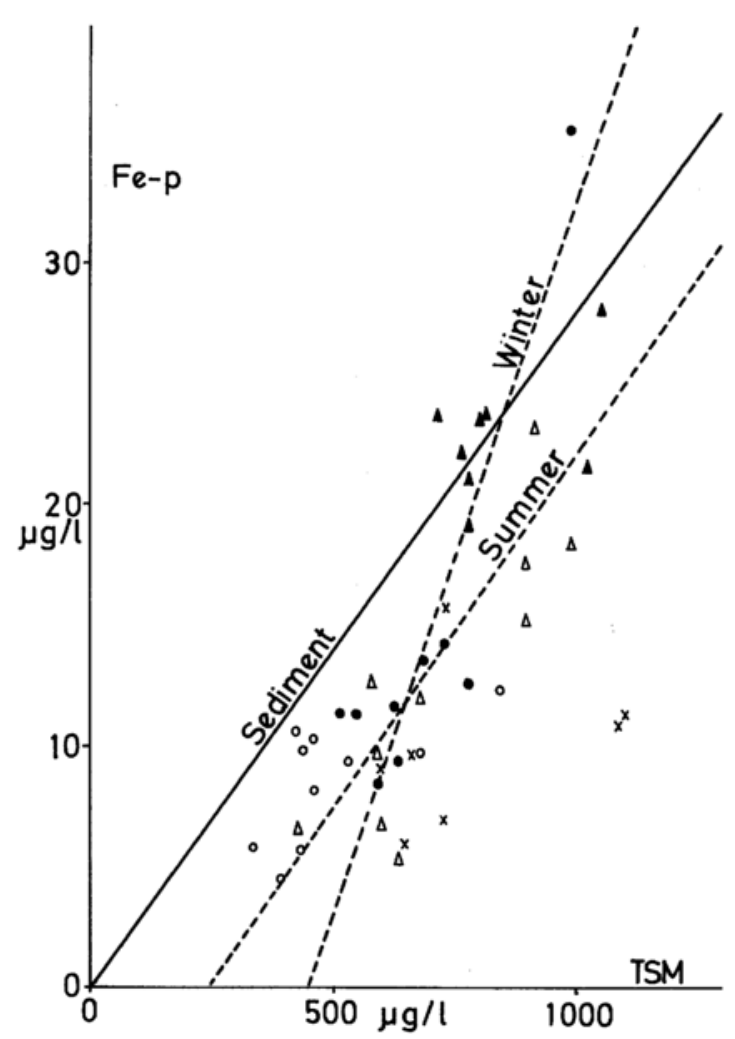

Fig. 6. Relation between particulate iron and total suspended matter (TSM), symbols and references are the same as in Fig. 5.

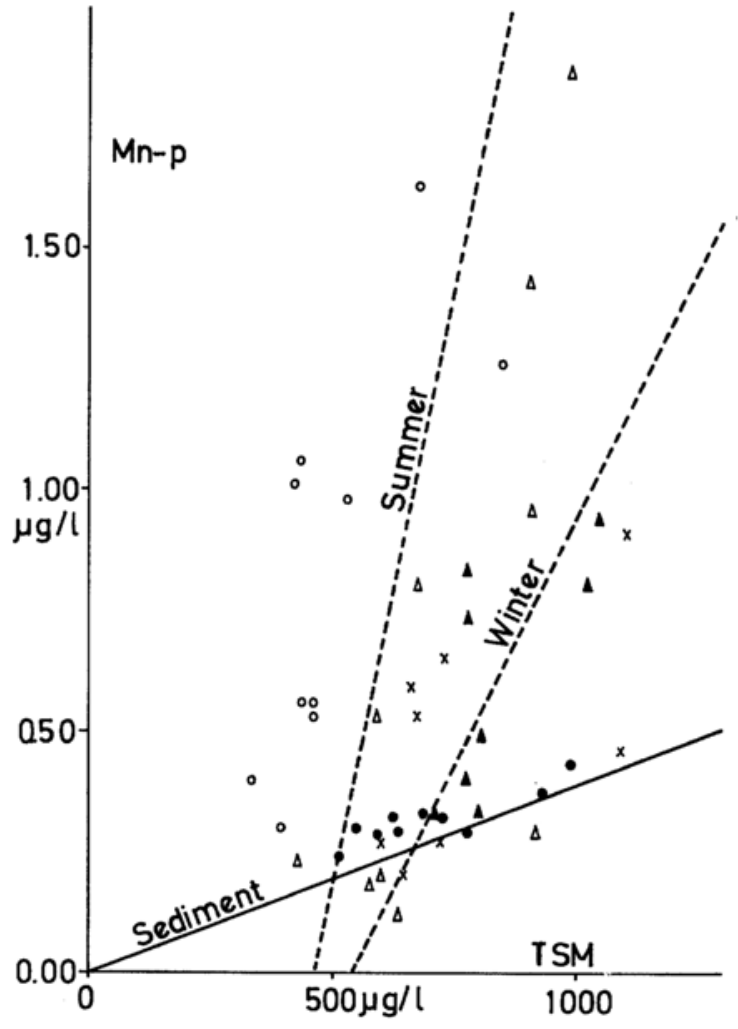

Fig. 7. Relation between particulate manganese and total suspended matter (TSM), sy:nbols and references are the same as in Fig. 5 .

Table 4. Mean concentrations of manganese, iron and aluminum in the particulate form in summer (28 August and 29 September) and winter (11 December and 6 February), and their insoluble and soluble fractions calculated by using the assumptions in the text.

\begin{tabular}{|c|c|c|c|c|c|c|c|}
\hline & \multirow{2}{*}{$\underset{\mu \mathrm{g} / 1^{*}}{\mathrm{TSM}}$} & \multicolumn{2}{|c|}{$\mathrm{Mn}$} & \multicolumn{2}{|c|}{$\mathrm{Fe}$} & \multicolumn{2}{|c|}{$\mathrm{Al}$} \\
\hline . & & $\mu \mathrm{g} / 1^{*}$ & $\mathrm{mg} / \mathrm{g}^{* *}$ & $\mu \mathrm{g} / 1^{*}$ & $\mathrm{mg} / \mathrm{g} * *$ & $\mu \mathrm{g} / \mathrm{l}^{*}$ & $\mathrm{mg} / \mathrm{g} * *$ \\
\hline \multicolumn{8}{|l|}{ Summer } \\
\hline $\begin{array}{l}\text { Total amount in } \\
\text { particulate form (A) }\end{array}$ & 650 & 0.79 & 1.2 & 11.2 & 17 & 2.5 & 3.9 \\
\hline Insoluble fraction (B) & 46 & 0.02 & 0.39 & 1.3 & 28 & 2.5 & 54 \\
\hline Soluble fraction (C) & 604 & 0.77 & 1.3 & 9.9 & 15 & 0.0 & $\equiv 0$ \\
\hline (C)/(A) & 0.93 & 0.97 & & 0.88 & & - & \\
\hline \multicolumn{8}{|l|}{ Winter } \\
\hline $\begin{array}{l}\text { Total amount in } \\
\text { particulate form (A) }\end{array}$ & 789 & 0.49 & 0.62 & 20.0 & 25 & 16.7 & 21 \\
\hline Insoluble fraction (B) & 309 & 0.12 & 0.39 & 8.7 & 28 & 16.7 & 54 \\
\hline Soluble fraction (C) & 480 & 0.37 & 0.77 & 11.3 & 24 & 0.0 & $\equiv 0$ \\
\hline$(\mathrm{C}) /(\mathrm{A})$ & 0.61 & 0.76 & & 0.57 & & - & \\
\hline
\end{tabular}

* $\mu \mathrm{g} / \mathrm{l}$; concentration of particulate form in seawater.

** $\mathrm{mg} / \mathrm{g}$; concentration of particulate form in particles. 
of the surface sediments but it does not lose its aluminum because of the inactive nature of aluminum during organic degradation or oxidation-reduction processes in the natural environment when the particulate matter is converted into sediment. The percentages of the lost fractions of metals in the particulate matter are calculated to be $97 \%$ for manganese and $88 \%$ for iron in summer and $76 \%$ for manganese and $57 \%$ for iron in winter as shown in Table 4. In summer, most of the particulate manganese settled in the bay dissolves on and/or in the bottom sediment and a part is transported to the open ocean. Iron is also lost from the particulate matter even in winter, although it is more difficultly reduced than manganese.

It is difficult to calculate the absolute amount of manganese dissolved on the sea floor from the sedimentation rate of aluminum in the bay, because the contribution of large alumino-silicate particles which are rapidly transported to the bottom is not well known. The soluble fraction, however, is expected to be closely related to organic or biogenic matter. We can therefore estimate the flux of metals to the bottom from the decomposition rate of organic matter on the sea floor. TsunOGaI et al. (1975) estimated the decomposition rate of organic carbon to be $25 \mu \mathrm{gC} / \mathrm{cm}^{2} /$ day from the rate of oxygen consumption in the bottom water in summer. According to Tsunogal and Arita (1975), the mean concentrations of TSM and its organic fraction, particulate organic matter (POM), are 710 and $370 \mu \mathrm{g} / 1$ respectively. By assuming that the POM contains $40 \%$ of organic carbon, the rate of particulate matter transported to the bottom is calculated to be

$$
25 \times \frac{710}{370 \times 0.40} \times 365=44 \mathrm{mg} / \mathrm{cm}^{2} / \mathrm{yr} .
$$

When an equilibrium state between the sedimentation and dissolution is attained, the rates of dissolution or loss of manganese and iron become

$$
44 \times 0.0013 \times 10^{3}=57 \mu \mathrm{g} / \mathrm{cm}^{2} / \mathrm{yr}
$$

for $\mathrm{Mn}$ $44 \times 0.015 \times 10^{3}=660 \mu \mathrm{g} / \mathrm{cm}^{2} / \mathrm{yr}$ for $\mathrm{Fe}$.

We have no data on the decomposition rate of organic matter in winter. The flux of particulate matter, however, can be calculated to be 53 $\mathrm{mg} / \mathrm{cm}^{2} / \mathrm{yr}$ if the mean settling velocity of particles in winter is equal to that in summer or the sedimentation rate to the bottom is proportional to TSM. This sedimentation rate of particulate matter results in dissolution rates of manganese and iron of 41 and $1.3 \times 10^{3} \mu \mathrm{g} /$ $\mathrm{cm}^{2} / \mathrm{yr}$ in winter, respectively. The rates averaged for the two seasons are therefore 49 and $1.0 \times 10^{3} \mu \mathrm{g} / \mathrm{cm}^{2} / \mathrm{yr}$ for manganese and iron, respectively. The rate of dissolution of manganese in Funka Bay is much smaller than the rate of $700 \mu \mathrm{g} / \mathrm{cm}^{2} / \mathrm{yr}$ observed by GRAHAM et al. (1976) in Narragansett Bay. The rates of introduction of these metals from the unit area of land to the ocean are $1.3 \mu \mathrm{g} / \mathrm{cm}^{2} / \mathrm{yr}$ for manganese and $75 \mu \mathrm{g} / \mathrm{cm}^{2} / \mathrm{yr}$ for iron (GoLDBERG and ARRHENIUS, 1958) which are 38 times for manganese and 13 times for iron smaller than the rates of supply from the unit area of coastal sea. Since the high rates of supply of these metals from the bottom sediment can not be covered by those from land, manganese and iron should be actively recycled in the coastal sea, producing solid phases in oxygenated seawater and dissolving in reducing sediments. The coastal current then transports a part of the metals in seawater to the pelagic ocean. The recent results show that the ratio of iron to aluminum in the oceanic water is higher than that in the mean crustal material (AlberTs et al., 1976), that is to say, the residence time of iron in the ocean is longer than that of aluminum. The supply of iron from coastal sea water to the pelagic ocean by the process mentioned above may be the chief cause of the longer residence time of iron compared to aluminum. Many text books of oceanography (e.g. RiLEY and Chester, 1971) have cited $2 \mu \mathrm{g} / 1$ as a mean concentration of manganese in seawater, which indicates the residence time of manganese to be a few thousand years. If this is so, we must consider the recycling of manganese in the pelagic ocean between sea water and sediments in addition to the processes operating in the coastal area. This problem needs to be discussed quantitatively using more precise data.

Acknowledgements-We wish to thank Prof. M.NISHIMURA for advice and to the staff of Laboratory of Analytical Chemistry, Faculty of Fisheries, Hokkaido University for their valuable discussion and help during the sampling. We are also indebted to Mr. N. SAKAGUCHI and the members of R/V Ushio Maru for helping our sampling.

\section{REFERENCES}

Alberts, J. M., Leyden, D. E. and Patterson, T. A. (1976) Distribution of total $\mathrm{Al}, \mathrm{Cd}, \mathrm{Co}, \mathrm{Cu}, \mathrm{Ni}$ and 
$\mathrm{Zn}$ in the tongue of the ocean and the northwestern Atlantic Ocean. Mar. Chem. 4, 51-56.

BeTZeR, P. R. and Pilson, M. E. Q. (1970) Concentrations of particulate iron in Atlantic open ocean water. J. Mar. Res. 28, 251-267.

BREWER, P. G. (1975) Minor elements in sea water. In Chemical Oceanography, 2nd ed. Vol. 1, ed. by J. P. RILEY and G. SKIrrow, Academic Press, London, 415-496.

Brewer, P. G., SPencer, D. W., Biscaye, P. E., Hanley, A., SAChS, P. L., Smith, C. L., KadAR, S. and FREDERICKS, J. (1976) The distribution of particulate matter in the Atlantic Ocean. Earth Planet. Sci. Lett. 32, 393-402.

GoldBerG, E. D., BRoECKER, W. S., Gross, M. G. and TUREKIAN, K. K. (1971) Marine chemistry. In Radioactivity in the Marine Environment, Natl. Acad. Sci. Washington D. C., 137-146.

GoldberG, E. D. and ARrhenius, G. O. S. (1958) Chemistry of Pacific pelagic sediments. Geochim. Cosmochim. Acta 13, 153-212.

Graham, W. F., Bender, M. L. and Klinkhammer, G. P. (1976) Manganese in Narragansett Bay. Limnol. Oceanogr. 21, 665-673.

Kester, D. R. (1972) Chemical form of iron in seawater. In Ferro-manganese deposits on the ocean floor ed. by D. R. HORN, 107-116.

KRAUSKOPF, K. B. (1957) Separation of manganese from iron in sedimentary process. Geochim. Cosmochim. Acta 12, 61-84.

Lewin, J. and Chen, C. (1973) Change in the concentration of soluble and particulate iron in sea water enclosed in containers. Limnol. Oceanogr. 18, 590-596.

MaITA, Y. and YanADA, M. (1977) Behavior of suspended organic matter in Funka Bay. In Interim report of study on the oceanography of Funka Bay, ed. by KAWAMURA, Hokkaido Univ., Hakodate, 27-34.

OHTANI, K. and AKIBA, Y. (1970) Studies on the changes of hydrographic conditions in the Funka Bay I. The annual change of the water of the bay. Bull. Faculty of Fisheries Hokkaido Univ. 20, 303312.

Price, N. B. and Calvert, S. E. (1973) A study of the geochemistry of suspended particulate matter in coastal waters. Mar. Chem. 1, 169-189.

RILEY, J. P. and ChESTER, R. (1971) Introduction to Marine Chemistry. Academic Press, London, $465 \mathrm{pp}$.

Sillen, L. G. (1961) The physical chemistry of seawater. In Oceanography ed. by M. SEARS, Publ. Am. Ass. Adv. Sci., 549-582.

SPENCER, D. W. and SACHS, P. L. (1970) Some aspects of the distribution, chemistry and mineralogy of suspended matter in the Gulf of Maine. Mar. Geol. 9, 117-136.

SPENCER, D. W., RobertSON, D. E., TUREKiAN, K.K. and Folsom, T. R. (1970) Trace element calibrations and profiles at the Geosecs test station in the Northwest Pacific Ocean. J. Geophys. Res. 75, 7688-7696.

STRICKLAND, J. D. H. and PARSONS, T. R. (1968) A practical handbook of seawater analysis. Bull. Fish. Res. Bd. Can. 167, 311 pp.

TAYLOR, S. R. (1964) Abundance of chemical elements in the continental crust. Geochim. Cosmochim. Acta 28, 1273-1286.

TSUNOGAI, S. and ARITA, H. (1975) Major inorganic element composition of suspended matter in Funka Bay. Paper presented at the spring meeting of Oceanogr. Soc. Japan, Tokyo April, 1975.

TSUNOGAI, S., KIDO, K., KONISHI, S., KUSAKABE, M. and SHINAGaWA, T. (1975) The rate of decomposition of organic matter in Funka Bay and the role of sea floor on it. Paper presented at the spring meeting of Oceanogr. Soc. Japan, Tokyo, April, 1975.

TSUNOGAI, S. and KUSAKABE, M. (1977) Migration of manganese in deep-sea sediments. Submitted to Processes at the ocean floor ed. by K. A. F ANNING and F. T. M ANHEIM.

Tsunogai, S., NoZaKi, Y. and Minagawa, M. (1974) Behavior of heavy metals and particulate matters in seawater expected from that of radioactive nuclides. J. Oceanogr. Soc. Japan 30, 209-220.

TsunogaI, S. and Shinagawa, T. (1977) Chemical components transported by the winter monsoon. Chikyu Kagaku (Geochemistry), 11, in press.

WILliAMS, P. M. (1969) The association of copper with dissolved organic matter in seawater. Limnol. Oceanogr. 15, 156-158. 